\title{
De las discusiones federales a los debates municipales: la edificación del constitucionalismo liberal en México, 1850-1873
}

\author{
From federal discussions to municipal debates: \\ the construction of liberal constitutionalism in Mexico, 1850-1873
}

\author{
Miriam Moreno Chávez ${ }^{1}$ (D) \\ El Colegio Mexiquense A. C.-México
}

Para citaciones: Moreno, M. (2020). De las discusiones federales a los debates municipales: la edificación del constitucionalismo liberal en México, 18501873. El taller de la Historia, 12(1), 2-27. DOI: $\underline{10.32997 / 2382-4794-v o l .12-n u m .1-2020-}$ $\underline{3200}$

Recibido: marzo de 2020

Aprobado: junio de 2020

Editor: Sergio Paolo Solano. Universidad de Cartagena-Colombia.

Tipología IBN Publindex:

Artículo de Investigación

Copyright: (c) 2020. Moreno, M. Este es un artículo de acceso abierto, distribuido bajo los términos de la licencia https://creativecommons.org/licenses/by-nc$\underline{\mathrm{sa} / 4.0 / \text { la cual permite el uso sin restricciones, }}$ distribución y reproducción en cualquier medio, siempre y cuando que el original, el autor y la fuente sean acreditados.

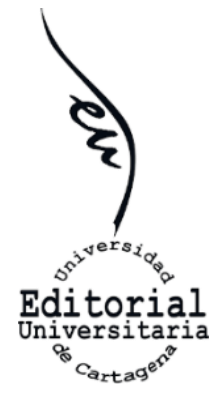

\section{RESUMEN}

El presente artículo analiza el constitucionalismo liberal de la segunda mitad del siglo XIX, desde un enfoque local. Se plantea la importancia de los poderes estatales y municipales en este proceso histórico, mostrando cómo el pacto federal de 1824, generó las condiciones para que cada entidad estatal creara un marco jurídico particular. Pone especial atención en los procesos políticos que se gestaron en el estado de Zacatecas, para explicar la participación e influencia del congreso local y los ayuntamientos en la discusión, la elaboración y la aplicación de los preceptos constitucionales de 1850 a 1873 . Se hace un seguimiento de los debates sobre la apertura política y la ejecución de las primeras elecciones directas en el estado, que revelan la interacción entre actores, instituciones, leyes y coyunturas políticas.

Palabras clave: liberalismo; constitucionalismo; municipio y federalismo.

\begin{abstract}
This work analyzes the liberal constitutionalism of the second half of the 19th century, from a local perspective. The importance of state and municipal powers in this historical process is described. This study described as the federal pact of 1824 generated the conditions for each state entity to create a particular legal framework. This research has a special focus on the political processes that took place in the state of Zacatecas, to explain the participation and influence of the local congress and city councils in the discussion, elaboration and application of the constitutional precepts from 1850 to 1873 . We are analysis of the debates on political openness and the implementation of the first direct elections in the state, which reveal the interaction between actors, institutions, laws and political situations.
\end{abstract}

Keywords: liberalism; constitutionalism; municipality and federalism.

1 miriam_201089@live.com.mx 


\section{INTRODUCCIÓN}

[...]la constitución ha debido ser la única luz que nos guie en la obra laboriosa de la reorganización [...] creemos que un minucioso apego por parte del gobierno a los preceptos de la Constitución y un respeto profundo a las garantías que ella asegura, a la vez que una saludable energía para reprimir los abusos que a su sombra se pretenda cometer, bastarán para hacer regular y expedita la marcha de la administración $[\ldots]^{2}$

La historia constitucional decimonónica está basada en un modelo legalista que se fundó sobre el valor supremo de la ley general y abstracta y del principio de legalidad; las constituciones fueron las encargadas de la organización de los poderes públicos y su equilibrio, a partir del establecimiento de un sistema de competencias formales. ${ }^{3}$ Existen ciertas generalidades significativas que dieron vida a este constitucionalismo liberal, como la herencia constitucional, discutida y elaborada en Cádiz en 1812, y la importancia de definir el territorio, la religión, la forma de gobierno, la ciudadanía la organización de los poderes públicos y el establecimiento de sus competencias; ${ }^{4}$ sin soslayar los procesos locales que fueron creando instituciones y leyes, sustentadas en un pensamiento jurídico, político y filosófico que adquirió variadas interpretaciones e imprimió un sello particular en cada territorio.

Su estudio ha sido tomado en cuenta ampliamente por historiadores y juristas, se han analizado con detenimiento los congresos constituyentes y sus derivadas constituciones nacionales, así como los procesos políticos que fueron guiando sus contenidos. Por un lado, la historiografía muestra que hay un mayor interés en aquellos periodos identificados con el establecimiento del federalismo mexicano y recientemente, con el constitucionalismo centralista e imperialista. Por el otro, cómo las instituciones y su conformación siguen siendo los temas predilectos, ignorando su desempeño y aplicación, así como los procesos acaecidos en las entidades estatales y el papel de los municipios en las discusiones y elaboraciones de los proyectos constitucionales locales ${ }^{5}$.

\footnotetext{
${ }^{2}$ Hemeroteca Nacional Digital de México (HNDM), La linterna mágica, Zacatecas, sábado 16 de mayo de 1868, Tomo I, No. 3.

${ }^{3}$ Ramón Ortega García, El derecho mexicano entre legalismo y constitucionalismo (anotaciones de historia constitucional), en Estudios de Historia Moderna y Contemporánea de México, No. 50, 2017, pp. 5-25, https://www.sciencedirect.com/science/article/pii/S0185262017300105

${ }^{4}$ Mariana Terán Fuentes, Bosquejo de un inmenso cuadro, liberalismo constitucional y formas de gobierno en Zacatecas, 1823-1845, México, UAZ, 2010, pp. 16-17.

${ }^{5}$ Algunos ejemplos de esta historiografía son los trabajos de Israel Arroyo y Reynaldo Sordo. Israel Arroyo, La arquitectura del estado mexicano: formas de gobierno, representación política y ciudadanía, 1821-1857, México, Instituto de Investigaciones Dr. José María Luis Mora, BUAP, 2011. Reynaldo Sordo Cedeño, El congreso de la primera república centralista, México, El Colegio de México, Instituto Tecnológico Autónomo de México, 1993. Catherine Andrews advierte cómo la historia constitucional forma parte de la historia del derecho y de la historia política, entendiéndose como el estudio de las leyes que regulan la organización política de un Estado, así como de las instituciones establecidas en virtud de estas leyes; pero también, como el análisis del pensamiento jurídico, político y filosófico que respalda las leyes y las instituciones de una constitución. Catherine Andrews, De Cádiz a Querétaro, historiografía y bibliografía del constitucionalismo mexicano, México, Fondo de Cultura Económica/Centro de Investigación y Docencia Económicas, 2017, pp. 9-17.
} 
Con la instauración de la República Federal en México en 1824, se decretó que "la soberanía reside radical y esencialmente en la nación" y se precisó cómo "sus partes integrantes son estados independientes, libres, y soberanos en lo que exclusivamente toque a su administración y gobierno interior". Se estableció en términos jurídicos una soberanía compartida entre los estados y el gobierno central, que puso a disposición de los gobiernos estatales la regulación y administración de sus respectivos municipios. ${ }^{6}$ Con la promulgación de La Constitución Federal de los Estados Unidos Mexicanos de 1824 , se crearon estados fuertes y con gran autonomía y un poder central debilitado, generando un proceso de competencia entre la federación, los estados y los municipios que llevaría a replantearse la forma de gobierno más conveniente para el país durante las siguientes décadas; definiendo de esta forma las características que distinguieron este constitucionalismo liberal, expuesto en las diferentes constituciones nacionales y locales que emergieron tras este contexto político.

El presente artículo busca hacer una aportación al estudio del constitucionalismo liberal, analizando los procesos y debates que tuvieron lugar en los núcleos estatales y municipales, en un periodo que permite revisar las discusiones previas y las aplicaciones posteriores a la Constitución política de 1857. Por cuestiones de carácter histórico-metodológicas tomaré como punto de referencia al estado de Zacatecas y sus municipios, debido a que cada entidad que conformó el pacto federal, creó sus propias constituciones y definió una reglamentación particular que enmarcó el funcionamiento de sus ayuntamientos. En este territorio en particular, los municipios fueron parte fundamental del sistema federal y su participación política se consideró ampliamente en la creación y reformulación del marco jurídico estatal. Desde 1825 se determinó que los ayuntamientos tuvieran la capacidad de proponer proyectos de ley en el congreso y de manifestar su opinión sobre cualquier asunto a discutirse, sin que ninguna ley pudiese decretarse "sin haber oído previamente los informes é impuestose[sic] de la opinión del gobierno y de los ayuntamientos[...]". ${ }^{7}$ Así, se pretende mostrar que las configuraciones de este constitucionalismo liberal estuvieron influenciadas por actores que hasta hace muy poco han sido tomados en cuenta por la historiografía. Su participación fue imprimiendo aspectos muy particulares en cada entidad del territorio mexicano, provocando la creación de un constitucionalismo plural que se definió por los procesos históricos gestados en cada estado.

El seguimiento de las propuestas, de las instituciones implicadas, de la reformulación o creación de leyes y su ejecución, permiten ver parte de este pensamiento jurídico, político y filosófico que reguló la organización política de México en los años de estudio; por esta razón, el artículo se compone de tres partes que abordan desde las discusiones constitucionales previas a 1857,

\footnotetext{
${ }^{6}$ Unidad General de Asuntos Jurídicos, Acta Constitutiva de la Federación Mexicana, Art. 3, Art 6 y Art. 79, http://www.ordenjuridico.gob.mx/Constitucion/antecedentes.php

7 Biblioteca Pública Elías Amador, (Zacatecas, México) (BPEA), Constitución Política del Estado Libre y Federado de Zacatecas, 1825 , Arts. 83 y 86.
} 
hasta la aplicación de las principales reformas después de 1869. La primera analiza cómo los planteamientos liberales de corte iusnaturalista que se venían discutiendo a nivel nacional, fueron permeando en la entidad zacatecana y llegaron a debatirse en la legislatura y los ayuntamientos del estado. La segunda, aborda los cambios que se vieron reflejados en las constituciones de 1857, poniendo especial atención a la evidente apertura política que se manifestó en la elección popular del jefe político, a la disminución de requisitos para ser considerado ciudadano y a los ajustes a las exigencias para que los pueblos pudiesen constituirse en municipios. Finalmente, la tercera parte explica cómo después del restablecimiento de la República, los legisladores zacatecanos y ayuntamientos impulsaron las elecciones directas, crearon un margen más amplio para la instauración de municipios y fueron aplicando estos preceptos constitucionales en el escenario local.

\section{1.- Hacia la amplitud de la democracia: los debates en torno a la constitución y el actuar de los gobiernos municipales, 1850}

Durante la segunda mitad del siglo XIX, tras haberse puesto en marcha distintas formas de gobierno, ${ }^{8}$ las exigencias de una reformulación constitucional a nivel nacional se hicieron presentes. La misma Carta Constitutiva de 1847 había advertido la necesidad de consolidar el sistema federal y hacerlo efectivo a través de una serie de modificaciones "que la experiencia ha demostrado ser necesarias". ${ }^{9}$ La historiografía plantea cómo desde la década de 1840 se fue discutiendo un constitucionalismo distinto al de 1824 , con la proyección de una república moderna sustentada en tres elementos: la idea de que la elección de presidente se hiciera por individuos, el derecho de petición como una medida individualista y la postulación de los derechos del hombre; exponiéndose así ciertas novedades como la sistematización de los derechos del individuo y del ciudadano, el bicameralismo con un senado moderador de la democracia en la cámara baja, la facultad del congreso de la unión para anular leyes estatales que contradijeran el pacto federal y la capacidad del poder judicial como garante de la constitucionalidad. Estas propuestas mantuvieron una continuidad con las discusiones en el Constituyente de 1835-1836 y marcaron un precedente inevitable para los congresos de 1847 y $1857^{10}$.

\footnotetext{
${ }^{8}$ El siglo XIX en México estuvo marcado por un prolongado proceso que tuvo como discusión central definir la forma de gobierno más adecuada para el país. Se pusieron en marcha diferentes opciones, se transitó del establecimiento de una república federal en 1824 -que en la práctica funcionó como un sistema confederalista- a una de carácter centralista en 1836, para después volver al restablecimiento del federalismo en 1846. El problema giró en torno a la prudencia de establecer una república federalista, confederalista o centralista que tuvo como trasfondo la definición de la soberanía y las competencias político-administrativas entre la federación y los estados. Esta problemática derivó en constantes enfrentamientos entre ambos poderes, y fue paralela a la discusión en cada territorio estatal sobre cómo compartir sus atribuciones con los gobiernos municipales. Mariana Terán Fuentes, Bosquejo de un inmenso cuadro, liberalismo constitucional y formas de gobierno en Zacatecas, 1823-1845, México, UAZ, 2015. Josefina Zoraida Vázquez, "El federalismo mexicano, 1823-1847", en Marcello Carmagnani (Coord.), Federalismo Latinoamericanos: México/Brasil/Argentina, México, El Colegio de México, Fideicomiso Historia de las Américas, FCE, 1996.

9 Unidad General de Asuntos Jurídicos, Acta Constitutiva y de Reformas, 18 de mayo de 1847, http://www.ordenjuridico.gob.mx/Constitucion/1843.pdf

${ }^{10}$ Arroyo encuentra en la nueva generación de constituyentes la idea de los derechos individuales como un precepto iusnaturalista, es decir, "como un conjunto de derechos imprescriptibles e inherentes al hombre y, por lo tanto, anterior a toda forma de gobierno y de Constitución", los cuales eran necesariamente generales y no podían ser quebrantados por
} 
En Zacatecas los debates constitucionales entre el congreso y los municipios, permiten ver este proceso. A partir de 1850 el legislativo y ayuntamientos se dieron a la tarea de discutir los cambios necesarios a la Constitución política del estado promulgada en 1832, que serían plasmados posteriormente en la Constitución política de 1852. Sometieron a discusión los artículos referentes a la elección del gobernador en el estado, plantearon por primera vez la participación ciudadana en las elecciones de los tres poderes, expusieron la necesidad de dotar a los gobiernos municipales de mayor autonomía y poder, y trataron temas como la elección del jefe político, la tolerancia religiosa, los derechos de los extranjeros, el derecho al voto y la consolidación del poder judicial $^{11}$.

En la Constitución Política del estado de 1832 la elección del gobernador implicó la participación de los ayuntamientos en el proceso, pues estaba establecido que cada cuatro años se reunirían en cabildo pleno y nombrarían tres individuos que tuvieran las cualidades constitucionales requeridas; después remitirían la nota de los elegidos al presidente del congreso autorizada con la firma del presidente, dos regidores y el secretario- quien la mostraría al resto de los diputados, para luego elegir al gobernador de entre los hombres nombrados por estas instituciones. En mayo de 1850 este procedimiento se puso en duda, el diputado Trinidad García de la Cadena argumentó su inconformidad sobre la intervención de los gobiernos municipales pues "sus individuos como se ve prácticamente desempeñan el empleo más bien por fuerza, y constantemente están con el empeño de renunciar o de separarse de cualquier otro modo del servicio". En su lugar proponía a las juntas electorales que estaban formadas por "individuos de más patriotismo y popularidad"12.

El diputado Raigosa se opuso a esta idea, considerando que la formación de las juntas electorales no era tan segura como las de los ayuntamientos. Las primeras eran nombradas y reunidas con un fin puramente político "no tienen jurisdicción alguna y están más expuestas a la influencia de los partidos mientras que los ayuntamientos tienen la misma popularidad y menos roce con los partidos". ${ }^{13}$ A esta posición se sumó el diputado Llamas convocando al congreso a la ampliación de las facultades de los gobiernos municipales, en conformidad con el sistema de gobierno adoptado. Puso de manifiesto las restricciones existentes sobre estas instituciones y las limitaciones de poder que habían impedido la participación de los hombres más capaces; también,

\footnotetext{
ninguna autoridad. I. Arroyo, "La Arquitectura", pp. 174 y 191. Por su parte, Marcello Carmagnani expone cómo la tensión existente entre los estados y la federación que prevaleció durante la primera experiencia federal y el centralismo, tendió a la conciliación, fuertemente influida por la difusión de la teoría jusnaturalista. Marcello Carmagnani, "El federalismo liberal Mexicano", en M. Carmagnani, Federalismo Latinoamericanos, pp. 136-144.

${ }^{11}$ Desde la Constitución de 1832 se determinó que en cada cabecera de partido habría un jefe político, éste sería nombrado por el gobernador de entre los individuos que en las diferentes ternas le propusieran los ayuntamientos y juntas municipales. Su principal función fue supervisar el funcionamiento de los ayuntamientos de sus respectivos partidos; tuvieron la capacidad de intervenir en los procesos electorales locales y presidir todas las reuniones realizadas con tal propósito; además de la capacidad de implicarse en asuntos municipales como los fondos públicos. Reglamento para el gobierno interior de los Partidos del Estado Libre de Zacatecas, 1825.

${ }^{12}$ Archivo Histórico del Estado de Zacatecas, (Zacatecas, México) (AHEZ), Poder legislativo, Actas de Sesiones del Congreso, 1850.

13 AHEZ, Poder Legislativo, Actas de Sesiones del Congreso, 1850.
} 
caracterizó al poder estatal como centralista e hizo un llamado a la amplitud de la democracia. ${ }^{14}$ Los legisladores Sandoval, Cenoz y Ulloa, encargados de elaborar el acta de reformas, formularon una propuesta que planteó la elección popular de todo el personal al servicio de los Supremos Poderes del Estado, mientras el diputado Aranda presentó un proyecto que sugería elecciones populares y directas para el gobernador y vicegobernador. ${ }^{15} \mathrm{De}$ esta forma se buscó que la participación de los municipios estuviera presente en el nombramiento de los tres poderes estatales, al proponer que los magistrados fueran electos por medio del voto ciudadano:

[...]no hay absolutamente razón para que en un sistema como el que tenemos se elijan los Poderes Legislativo y Ejecutivo popularmente y el Judicial lo sea tan solo por el Congreso, que semejante conducta adquiría también una anomalía en la Constitución porque dimanando la soberanía inmediatamente del pueblo y representándose ésta en el Estado por los tres poderes Supremos es preciso que todos ellos dimanen también de los ciudadanos[... $]^{16}$

Tales cambios fueron debatidos nuevamente por otros diputados que los consideraron como "el mayor de los males que se le puede hacer sufrir", pues al lanzar a la política al poder judicial, se ponía en "la mano a los partidos políticos el arma más peligrosa y desmoralizadora que hasta hoy se ha conocido". ${ }^{17}$ Respecto a la elección de los jefes políticos, los diputados Llamas y Rodríguez propusieron que no se modificara, sino que siguieran siendo "postulados por los Ayuntamientos y Juntas Municipales y nombrados por el gobierno, porque teniendo estos funcionarios su origen en la opinión pública es seguro que son más a propósito para acatarla y consultarla". La oposición señaló las desventajas que este procedimiento implicaba, argumentando que las ternas propuestas por los ayuntamientos "comienzan por el inconveniente de fomentar el aspirantismo" debido al gran número de individuos que se propondrían tomando en cuenta a cada ayuntamiento, además "atendiendo a que los jefes políticos no son más que puros agentes del gobierno a que por lo mismo deben ser personas que merezcan toda su confianza", al no ser elegidos directamente por el gobernador "no puede haber unidad ni regularidad en la marcha de la administración" 18 .

El congreso se encontraba dividido, había diputados con una postura moderada y otros con ideas radicales. Los primeros buscaron efectuar cambios constitucionales, pero sin otorgarles mayores atribuciones a los ayuntamientos, quisieron crear un equilibrio que los mantuviera

\footnotetext{
${ }^{14}$ AHEZ, Poder Legislativo, Actas de Sesiones del Congreso, 1850.

${ }^{15}$ AHEZ, Poder Legislativo, Comisión de Puntos Constitucionales, Acta de reformas a la constitución del Estado presentados por los diputados Sandoval, Cenoz y Ulloa, Junio-Julio, 1850. AHEZ, Poder Legislativo, Comisión de Puntos Constitucionales Proyecto del acta de reformas presentada por el diputado Aranda, Julio de 1850.

${ }^{16}$ AHEZ, Poder Legislativo, Actas de Sesiones del Congreso, 1850.

${ }^{17}$ AHEZ, Poder Legislativo, Actas de Sesiones del Congreso, 1850.

${ }^{18}$ AHEZ, Poder Legislativo, Leyes, Decretos y Reglamentos, Proyecto de reglamento económico político y de policía para los partidos del estado y algunas observaciones, 1851.
} 
subordinados al poder estatal, pero con ciertos rasgos de autonomía. Por su parte, el grupo radical consideró que la libertad de los gobiernos municipales y la participación constante de los pueblos, conduciría a la implementación plena del federalismo.

En enero de 1850, el congreso hacía referencia a las aportaciones de los municipios sobre el proyecto de reformas constitucionales, con las cuales se buscaba "consolidar el sistema, purgando a la constitución de todos aquellos defectos que la experiencia ha hecho conocer hasta hoy". Su colaboración era de suma importancia "pues es casi indispensable oír de los pueblos, representados por sus legítimas autoridades todas aquellas observaciones que indiquen a lo menos las reformas convenientes a su mejor provecho según sus circunstancias locales, sus costumbres y hábitos particulares". ${ }^{19}$ De los 37 ayuntamientos existentes en el estado más de la mitad enviaron sus opiniones y propuestas: Chalchihuites, Sain Alto, Sombrerete, Villanueva, Jalpa, Villa del Refugio, Zacatecas, Vetagrande, Guadalupe, Nieves, Río Grande, Aguascalientes, Tlaltenango, Tepechitlán, Estanzuela, Momax, San Juan del Teúl, Jerez, Juchipila, Moyahua, Calvillo, Rincón de Romos y Sauceda.

Las reflexiones se centraron principalmente en cuatro puntos: la religión, las garantías y derechos de los extranjeros, el derecho al voto y la consolidación del poder judicial. Dentro de los cambios expuestos por el congreso, se encontraba la omisión sobre cuál sería la religión oficial, con el propósito de impulsar la tolerancia religiosa, al señalarse que "la religión del estado es la misma que la de la federación". Si bien, consideraron la libertad de culto como una reforma necesaria, tenían presente que "este es uno de los vínculos de unión con los pueblos todos que forman la confederación mexicana, que no le es dado variar a los estados sin atacar la constitución general". Este cambio encuentra su origen en la idea de mantener y salvaguardar los derechos del individuo, pues "la comisión ha creído que no debería en lo absoluto excluir de la comunión política a los que por desgracia profesan creencias religiosas diversas de las del Estado, y por eso y por proteger hasta donde sea posible el aumento de la población, llama a gozar de las garantías y derechos de los ciudadanos zacatecanos" 20 .

A pesar de que la modificación no fue tan radical los ayuntamientos expresaron su inconformidad. Por ejemplo, el de Zacatecas manifestó la necesidad de establecer constitucionalmente que la católica fuera la oficial; su postura fue de carácter moderado, pues aun mostrando cierto desagrado, no descartó la posibilidad de efectuarla en años venideros: "aunque parece que sus autores están por la tolerancia [...] las exigencias de la época lo harán tal vez necesario, pero por ahora, quizá es prudente atender a la voluntad de los pueblos declarada unánime en favor de la católica". El gobierno de

\footnotetext{
${ }^{19}$ AHEZ, Jefatura Política, Gobierno del estado, 1850.

${ }^{20}$ AHEZ, Poder Legislativo, Leyes, Decretos y Reglamentos, 1849.
} 
Chalchihuites dejó claro que "no quisiera reconocer ni admitir una tolerancia por temor de una rebelión; y entonces la consignación de la intolerancia en su pacto constitucional era una garantía para su religión". ${ }^{21}$ Sain Alto fue más radical al advertir que "la religión católica apostólica romana, ha sido, es y será para la Nación el tesoro más precioso que puede tener; porque ella más que el temor del castigo que imponen las leyes civiles, hacen que los pueblos se moralicen y cumplan sus deberes sociales". La mayoría de los gobiernos municipales refutaron esta propuesta, por tal motivo en la Constitución de 1852 quedó decretado que la "religión del Estado de Zacatecas es y será perpetuamente la católica, apostólica romana, sin tolerancia de otra alguna" 22 .

La idea de concederle a los extranjeros derechos constitucionales que permitieran su participación en algún cargo público, fue otra de las reformas rechazadas rotundamente. El ayuntamiento de Zacatecas consideró contraproducente el caos legislativo imperante para esta disposición; también reconoció que los puestos gubernamentales debían ser ocupados por sujetos con un conocimiento amplio de las exigencias de cada población, característica exclusiva de los mexicanos. ${ }^{23}$ Sain Alto precisó que "no veremos con agrado que un extranjero nos dé leyes y nos gobierne cuando dentro de nosotros mismos tenemos ciudadanos ilustrados llenos de patriotismo y amados por los pueblos". ${ }^{24}$ La oposición a este cambio evitó nuevamente que apareciera promulgado en la Constitución política de 1852.

El derecho al voto también se puso a discusión en el proyecto. El congreso restringió la ciudadanía únicamente a los que supieran leer y escribir, al considerarse cómo la población que no contaba con esta condición era fácil de manipular; sirviendo también "de estímulo para salir de esa ignorancia en que están sumergidas las masas, que las hace servir nada más que de ciego instrumento de las facciones que aún dividen al Estado". ${ }^{25}$ Los ayuntamientos expusieron la injusticia que representaba limitarlo, consideraban que el gobierno era responsable de no haberse "dictado la menor medida para que los c.c. salgan de la ignorancia, para que se les infunda el patriotismo, para que se reanime el espíritu público”, por tales motivos esta ley resultaba inadecuada. Las razones por las que se oponían resultaban muy evidentes pues de aplicarse esta reforma "la supresión de los derechos de ciudadano a los que no sepan leer y escribir va a reducir el número hasta un grado que habrá pueblos en el Estado que sólo contarán con quince o veinte ciudadanos". ${ }^{26}$ Esto reducía en gran medida la representación política, pero una vez más los gobiernos municipales se impusieron y la

\footnotetext{
${ }^{21}$ AHEZ, Poder Legislativo, Comisión de Constitución, Observaciones al proyecto de reformas a la Constitución por los partidos del estado, 2 de marzo de 1850.

${ }^{22}$ Guillermo Huitrado Trejo (Coord.), Zacatecas y sus constituciones, Zacatecas, Gobierno del Estado, UAZ, 1996, p.48.

${ }^{23}$ AHEZ, Jefatura Política, Gobierno del estado, 1850.

${ }^{24}$ AHEZ, Poder Legislativo, Comisión de Constitución, Observaciones al proyecto de reformas a la Constitución por los partidos del estado, 1850.

${ }^{25}$ AHEZ, Poder Legislativo, Leyes Decretos y Reglamentos, 1849.

${ }^{26}$ AHEZ, Poder Legislativo, Comisión de Constitución, Observaciones al proyecto de reformas a la Constitución por los partidos del estado, 1850 .
} 
disposición no apareció y en la Constitución de 1852, los requisitos para ser ciudadano fueron únicamente haber nacido en el estado o avecindado a él, tener un modo honesto de vivir, no tener proceso criminal y haber cumplido 21 años de edad, desapareciendo el de saber leer y escribir.

Finalmente presentaron su opinión sobre la corrupción, inestabilidad y desorganización del poder judicial que "se varía al arbitrio y paladar de las autoridades", por eso "funestas han sido las consecuencias de este mal, que considerado en su esencia no puede menos que atribuirse a su elección antipopular". Propusieron terminar con la capacidad otorgada al poder legislativo para la creación de tribunales y la variación de su forma; asimismo, la instauración de un jurado para la resolución de los juicios, ya que "los ciudadanos temen sujetar sus diferencias a la decisión de los tribunales, porque según se expresan, en ellos el más poderoso, el que tenga mayores recomendaciones obtendrá el fallo". ${ }^{27}$ El poder judicial había recibido muy poca atención por parte del congreso y del ejecutivo a la hora de formular sus atribuciones, como había sucedido también en el congreso federal. De los tres poderes fue el más debilitado y el menos organizado, debido a eso recibió mayor atención en la Constitución de 1857.

El acta de reformas a la Constitución política del estado de 1850 y la Constitución política del Estado Libre de Zacatecas de 1852, fueron el resultado de estas discusiones, aunque predominaron las ideas moderadas también aparecieron algunas demandas de los radicales. Se estableció que los nombramientos de los magistrados y del fiscal del Supremo Tribunal de Justicia se harían en lo sucesivo por el congreso a propuesta en terna de los ayuntamientos y juntas municipales. También se dispuso que los jueces de letras serían electos por el Supremo Tribunal, nuevamente a sugerencia de estas instituciones. No obstante, en la elección del gobernador las opiniones moderadas se impusieron al determinarse "por los electores secundarios o de partidos", desapareciendo así el procedimiento planteado por la Constitución de 1825. Lo más novedoso fue la precisión de que "los votos se emitirán individualmente y no por juntas", pues las elecciones se habían basado hasta el momento en procesos colectivos ${ }^{28}$.

La idea del individuo estaba ya presente, por lo que es posible observar un paso hacia un constitucionalismo liberal de corte iusnaturalista que ya se venía discutiendo en los debates nacionales desde el Constituyente de 1842, en el cual sobresale la noción de que el presidente de la república se elegiría por individuos y no por colectivos. ${ }^{29}$ Las discusiones nacionales y estatales fueron la antesala de los principales cambios expresados en los planes

\footnotetext{
${ }^{27}$ AHEZ, Jefatura Política, Gobierno del estado, 1850.

${ }^{28}$ G. Huitrado, "Zacatecas", p. 45.

${ }^{29}$ Norberto Bobbio explica que la teoría iusnaturalista se sustentó en tres postulados básicos: 1) la idea de los individuos como la fuente última de toda autoridad gubernamental; 2) la función primera de todo gobierno es el mantenimiento y protección de los derechos naturales; y 3) cómo estos últimos establecen límites a la autoridad de los gobiernos. Norberto Bobbio, Pensar la Democracia, México, Universidad Autónoma de México, 2007, p.161.
} 
constitucionales de 1857 y guiaron el constitucionalismo de las siguientes décadas.

\section{2.- De los derechos del hombre a la apertura política, 1857}

La Constitución Federal de los Estados Unidos Mexicanos, promulgada en 1857, ha sido caracterizada por la historiografía como la más novedosa del siglo XIX y en la que se puede observar una mayor discontinuidad respecto a la Constitución de 1824; tanto por su contenido como por la composición del congreso, el cual estuvo conformado exclusivamente por liberales. ${ }^{30}$ En ella encontramos una serie de ideas que no habían sido plasmadas constitucionalmente, pero cuyos planteamientos se venían gestando desde la década de 1840 como se señaló anteriormente.

Israel Arroyo explica las continuidades y discontinuidades que mantuvo el contenido de esta constitución respecto a las de 1824 y 1835: para el derecho de petición (práctica consuetudinaria) la innovación consistió en su aprobación constitucional; mientras las garantías individuales tuvieron un precedente o influencia tanto del constitucionalismo de 1823-1827 como del de 1836. Lo novedoso fue la enmienda iusnaturalista, la federalización de dichos derechos y pensar cómo garantizarlos en lo concreto. La forma de elección del presidente se distancia completamente de los dos proyectos constitucionales anteriores, porque se buscó dejar atrás la determinación de las legislaturas conforme a los modelos de 1824 y 1836. Por su parte, Marcello Carmagnani sostiene que entre el federalismo de 1824 y el de 1857 hay una mayor discontinuidad, debido a que el primero dio vida a una federación con poderes dotados de escasas competencias, mientras que el segundo se caracterizó por un proceso de conciliación entre quienes buscaban la descentralización y centralización de los poderes federales y por la progresiva difusión de la teoría iusnaturalista, garante de los derechos del hombre ${ }^{31}$.

En abril de 1856 la prensa municipal de Zacatecas enfatizaba la importancia de la Revolución de Ayutla para la nación mexicana, precisando que "llevó como único objeto desde su iniciación hasta que se consumara, constituir a México para salvar así su nacionalidad, para asegurar las instituciones que se impusiera según su voluntad soberana, para afianzar su borrascoso porvenir". Esto requería la reformulación de la Constitución General, cuya tarea correspondía a aquellos representantes elegidos por el pueblo y sobre quienes recaía toda obligación: "[...]se han depositado en las manos del congreso y por lo mismo suya y nada más que suya será la responsabilidad; si violando

\footnotetext{
30 Erika Pani hace referencia a la composición del constituyente, destacando dos cuestiones esencialmente: 1) la conformación exclusiva de liberales, producida por la cooptación de los gobiernos locales y la negación del voto a los miembros de las órdenes regulares y a los sacerdotes seculares; 2) advierte cómo en los debates del congreso los legisladores tomaron diferentes posturas frente a cada asunto a discusión, de modo que no se formaron dos grupos enfrentados como la historiografía ha planteado. Erika Pani, Una serie de admirables acontecimientos, 1848-1867, México, Educación y Cultura, Benemérita Universidad Autónoma de Puebla, 2013, pp. 66-67.

${ }^{31}$ I. Arroyo, "La Arquitectura", pp. 178-195. M. Carmagnani, "El federalismo", pp. 136-141.
} 
los compromisos que ha aceptado, no llena las exigencias del pueblo, no cubre las necesidades de nuestra sociedad, no corresponde a la confianza de la patria que le llamó en las horas suprema de su angustia y agonía". ${ }^{32}$ De esta forma los estados y los municipios fueron entrando a la discusión sobre las modificaciones constitucionales que marcaron el devenir de las siguientes décadas del siglo.

Las demandas constitucionales de los municipios se distinguieron por mantenerse bajo un esquema liberal. Se plantearon aquéllas que buscaron proteger los derechos del hombre, tales como la igualdad y la libertad de todos los hombres por razón de nacimiento, la libertad de pensamiento en la palabra, escritura e imprenta y la libertad de la propiedad, del comercio y de la industria. Las más novedosas estuvieron asociadas con la apertura política, proponiéndose "la admisión de todos los ciudadanos a los empleos civiles, eclesiásticos y militares, sin más distinción que la del mérito o elección legítima popular" y "la libertad para formar asociaciones y círculos políticos, salvo la vigilancia municipal" 33 .

Algunas de estas exigencias las vemos plasmadas en la Constitución Federal de 1857. Por ejemplo, en la primera sección se decretaron los derechos del hombre, que representaron la "base y el objeto de las instituciones sociales"; se impusieron las libertades del hombre al nacer, la de enseñanza, la de manifestación de ideas, la libertad de imprenta, la portación de armas para su defensa, la abolición de la pena de muerte y penas de mutilación y de infamia. Los artículos 8 y 9 significaron un gran avance en materia de apertura política, el primero expuso la inviolabilidad del derecho de petición al ser ejercido por escrito "de una manera pacífica y respetuosa", señalando que en materia política sólo podían hacer uso de él los ciudadanos de la república, también se advirtió que "a toda petición debe recaer un acuerdo escrito de la autoridad a quien se haya dirigido, y ésta tiene obligación de hacer conocer el resultado al peticionario". Mientras que el artículo 9 expuso que "a nadie se le puede coartar el derecho de asociarse o de reunirse pacíficamente con cualquier objeto lícito; pero solamente los ciudadanos de la república pueden hacerlo para tomar parte en los asuntos políticos del país". ${ }^{34}$ Estas estipulaciones encontraron un antecedente en las exigencias para ampliar la representación política, permitiendo que los ciudadanos tuvieran mayor participación en las cuestiones de carácter político, abriendo así un margen considerable a las demandas y objeciones de la población; como se dejó ver en los debates constitucionales de 1850 .

Por tal motivo, también se concretó en la Constitución Federal de 1857 la reducción de requisitos para acceder a la ciudadanía, al imponerse únicamente dos: haber cumplido dieciocho años siendo casado y veintiuno si no lo fueran

\footnotetext{
${ }^{32}$ Archivo Histórico Municipal de Zacatecas (Zacatecas, México) (AHMZ), Colecciones, Donación del Dr. José Enciso Contreras, Periódico, El Pobre Diablo.

${ }^{33}$ HNDM, El Pobre Diablo, Tlaltenango, sábado 9 de mayo de 1856, Tom0o I, Núm. 23.

${ }^{34}$ Unidad General de Asuntos Jurídicos, Constitución Federal de los Estados Unidos Mexicanos, 1857, Sección I., http://www.ordenjuridico.gob.mx/Constitucion/1857.pdf
} 
y tener un modo honesto de vivir. Se eliminaron los concernientes a la renta anual y saber leer y escribir (tabla 1). Aumentó el número de diputados en referencia a la población al establecerse uno por cada cuarenta mil habitantes, esto permitió un número mayor de representantes estatales en el Congreso Nacional. No obstante, respecto al tema de las elecciones directas los constituyentes de 1856 fueron mucho más mesurados; algunos congresistas como Zarco defendieron ampliamente su concreción constitucional, por considerar que las elecciones indirectas "se presta a influencias bastardas, a la coacción ministerial, a toda clase de intrigas"; también por ser "un artificio para engañar al pueblo, haciéndole creer que es elector y empleándolo en criar una especie de aristocracia electoral que, mientras más se eleva en grados, más se separa del espíritu y de los intereses del pueblo". Por su parte Arriaga advirtió el problema de la "carencia de costumbres políticas" y Olvera expuso cómo su aplicación debía realizarse "cuando la población presente un carácter homogéneo. Entre tanto, si se establece el sufragio directo, tampoco expresará la voluntad pública", pues resultaba evidente cómo "los sirvientes de hacienda votarán como quiera el propietario y los que viven como esclavos en las panaderías no tendrán voluntad propia. Menester es esperar la emancipación de estas clases desgraciadas"35.

Tabla 1: Requisitos para obtener la ciudadanía

\begin{tabular}{|c|c|}
\hline Constitución o Acta & Requisitos \\
\hline $\begin{array}{l}\text { Constitución federal de } \\
\text { los Estados Unidos } \\
\text { Mexicanos, } 1824\end{array}$ & $\begin{array}{l}\text {-Las cualidades de los electores se prescribieron } \\
\text { constitucionalmente por las legislaturas de los estados (a } \\
\text { las que también correspondió reglamentar las elecciones). } \\
\text { (Art.9) }\end{array}$ \\
\hline $\begin{array}{l}\text { Leyes constitucionales } \\
1836\end{array}$ & $\begin{array}{l}\text {-Ser mexicano por nacimiento o por naturalización. } \\
\text {-Tener una renta anual lo menos de cien pesos, procedentes } \\
\text { de capital fijo, mobiliario, de industria o trabajo personal } \\
\text { honesto y útil a la sociedad. } \\
\text { - Los que hayan obtenido carta especial de ciudadanía del } \\
\text { Congreso general, con los requisitos que establezca la ley. }\end{array}$ \\
\hline $\begin{array}{l}\text { Bases de la } \\
\text { organización política de } \\
\text { la república mexicana, } \\
1843\end{array}$ & $\begin{array}{l}\text {-Ser mexicano y haber cumplido } 18 \text { años siendo casado y } \\
21 \text { si no lo han sido } \\
\text {-Tener una renta anual de } 200 \text { pesos por lo menos, } \\
\text { procedente de capital físico, industria o trabajo personal } \\
\text { honesto. } \\
\text {-Los congresos constitucionales podrán arreglar, según las } \\
\text { circunstancias de los departamentos, la renta que en cada } \\
\text { uno de éstos haya de requerirse para gozar los derechos de } \\
\text { ciudadano. } \\
\text { - Desde el año de } 1850 \text { en adelante los que llegaren a la } \\
\text { edad que se exige para ser ciudadano, es necesario que } \\
\text { sepan leer y escribir. }\end{array}$ \\
\hline $\begin{array}{l}\text { Acta constitutiva y de } \\
\text { reformas, } 1847\end{array}$ & $\begin{array}{l}\text {-Ser mexicano por nacimiento o por naturalización. } \\
\text {-Tener la edad de } 20 \text { años } \\
\text {-Tener un modo honesto de vivir }\end{array}$ \\
\hline
\end{tabular}

${ }^{35}$ Francisco Zarco, Congreso extraordinario constituyente, 1856-1857, México, Secretaría de Gobernación, 1979, pp. 604608 . 
Constitución Federal de Los Estados Unidos Mexicanos de 1857
-No haber sido condenado en proceso legal a alguna pena infamante.

-Haber cumplido 18 años siendo casado o 21 si no los son -Tener un modo honesto de vivir

Fuente: Unidad General de Asuntos Jurídicos, Constitución Federal de los Estados Unidos Mexicanos 1824, Leyes Constitucionales 1836, Bases de la organización política de la República Mexicana, 1843, Acta Constitutiva y de Reformas 1847, Constitución Federal de los Estados Unidos Mexicanos de 1857, http://www.ordenjuridico.gob.mx/Constitucion/antecedentes.php

En el estado de Zacatecas se mantuvieron los mismos parámetros constitucionales en comparación con la Constitución local de 1852, únicamente se incluyó el fragmento que admitió como ciudadanos a los hombres casados de 18 años. Es posible apreciar una tendencia a aumentar su número desde 1852, cuando desapareció el requisito de saber leer y escribir; además de que nunca se impuso la obligación de tener una renta anual mínima. Para la elección de diputados los requerimientos no variaron mucho de una constitución a otra; solamente la de 1825 estableció que "se necesita ser ciudadano en el ejercicio de sus derechos, de veinticinco años de edad a los menos, natural o vecino del partido que lo nombra, en el que deberán gozar el concepto de propiedad e instrucción", ${ }^{36}$ mientras el resto determinó "ser ciudadano en ejercicio de sus derechos, tener veinticinco años cumplidos, ser vecino del estado". ${ }^{37}$ Se suprimieron el concepto de propiedad e instrucción y la condición de ser vecino o natural del partido; en su lugar, sólo se impuso la de vecindad. Vale la pena prestar atención a las continuidades que se observan entre las distintas constituciones locales sobre los requisitos para ser considerado ciudadano, pues en las cuatro permanecen el de vecindad, tener un modo honesto de vivir y hasta 1852 el de no tener un proceso criminal. Mientras que las discontinuidades se concentran en la edad para alcanzar la ciudadanía y en la referente a la instrucción (ver tabla 2).

Tabla 2. Requisitos para ser considerado ciudadano en el Estado de Zacatecas, 1825-

$$
1857
$$

\begin{tabular}{|ll|}
\hline Constitución Política del & -Haber nacido en el estado o avecindado a él. \\
Estado Libre de Zacatecas, & -Tener un modo honesto de vivir. \\
1825 & -No ser procesado criminalmente. \\
& -Tener 21 años de edad. \\
& - Del año de 1840 en adelante saber leer y escribir. \\
\hline & -Haber nacido en el estado o avecindado a él. \\
Constitución Política del & -Tener un modo honesto de vivir. \\
Estado Libre de Zacatecas,, & -No ser procesado criminalmente. \\
1832 & -Tener 21 años de edad. \\
& - Del año de 1840 en adelante saber leer y escribir. \\
\hline Constitución Política del & -Haber nacido en el estado o avecindado a él. \\
Estado Libre de Zacatecas,, & -Tener un modo honesto de vivir \\
1852 & -No tener proceso criminal \\
& -Haber cumplido 21 años de edad \\
\hline
\end{tabular}

${ }^{36}$ BPEA, Constitución Política del estado libre y federado de Zacatecas, 1825, Art. 20.

${ }^{37}$ G. Huitrado, "Zacatecas", p.60. 


\section{Constitución Política del Estado Libre de Zacatecas, 1857 \\ -Haber nacido en el estado o avecindado a él. -Haber cumplido 18 siendo casado, o 21 si no lo son. -Tener un modo honesto de vivir}

Fuente: G. Huitrado, “Zacatecas", pp. 28-73. BPEA, Constitución Política del Estado Libre y Federado de Zacatecas, 1825.

Respecto al ámbito municipal, en el estado se redujo el número de habitantes para poder erigirse en uno, al decretarse que en adelante fueran más de dos mil, cuando anteriormente se había establecido en tres mil; ${ }^{38}$ esto produjo un aumento de ayuntamientos a partir de 1857. Para 1853 el estado contaba con 33 municipalidades y 11 partidos, mientras que para 1863 su número había aumentado a 36 municipalidades y 12 partidos. Estas características son coincidentes con un contexto nacional que fue abriendo de manera progresiva los espacios de participación política, y así ir integrando al mayor número de hombres al proceso de ciudadanización. ${ }^{39}$ En el artículo 50 constitucional también se determinó que "toda población de más de dos mil habitantes que se halle en terreno de propiedad particular, tiene derecho a que se le venda el que necesita para ejidos, y constituirse en municipalidad". ${ }^{40}$ Esta estipulación permitió que una cantidad importante de poblados ubicados en propiedad de los hacendados, pudieran solicitar la erección de su municipio y la dotación de ejidos para su consolidación.

Aunque la apertura política fue una modificación nacional, lo cierto es que cada entidad federativa experimentó un proceso diferente que se distinguió por una mayor o menor amplitud. Por ejemplo, Ma. del Carmen Salinas Sandoval explica la forma en la cual se llevó a cabo en el Estado de México, advirtiendo cómo la legislación municipal respondió a las esferas nacional y estatal. Ambas influyeron para que las prácticas políticas municipales tuvieran una trayectoria dirigida a vincular la vida local con la estatal y ésta con la nacional; esto explica por qué en esta entidad la participación se vio más restringida en comparación al caso zacatecano, pues el concepto de ciudadanía siguió vinculado con las ideas de trabajo, a no tener deudas, a administrar adecuadamente los bienes y a saber leer y escribir ${ }^{41}$.

La elección de los cargos del Poder Judicial y los jefes políticos también se vio modificada en la Constitución local de 1857. El congreso restringió toda intervención de los ayuntamientos en lo concerniente al Poder Judicial, pero por primera vez determinó la elección directa para las jefaturas políticas. Las constituciones de 1832 y 1852 habían estipulado que en cada cabecera "habrá un Jefe Político que nombrará el Gobierno de entre los individuos que en las diferentes ternas le propongan los respectivos ayuntamientos y juntas

\footnotetext{
38 G. Huitrado, "Zacatecas", p. 63.

${ }^{39}$ Erika Pani hace referencia a este contexto europeo y otros países de América en el que prevaleció la lucha por la participación política durante la década de 1840, refiriéndose a las revoluciones que tuvieron lugar en 1848, con el afán de unificar los espacios nacionales y reforzar los lazos que vinculaban a la comunidad nacional, y unían a éstas con el Estado. Erika Pani, "Una serie", pp.31-38.

${ }^{40}$ G. Huitrado, "Zacatecas", p.71

${ }^{41}$ Ma. del Carmen Salinas Sandoval, Política y sociedad en los municipios del estado de México (1825-1880), México, El Colegio Mexiquense, 1996, pp.59-73.
} 
municipales, y su duración será de cuatro años, pudiendo ser reelecto indefinidamente". Con el propósito de incluir a los gobiernos municipales y a los ciudadanos en las decisiones referentes a su régimen interior y limitar el margen de poder que tenían estas figuras, se precisó que "en cada cabecera de Partido habrá un jefe político que durará cuatro años, será nombrado popularmente en los términos que diga la ley electoral y no podrá ser reelecto hasta que pase igual periodo de elección" 42 .

Las discusiones sobre las elecciones directas en el estado continuaron después de finalizarse la Guerra de Reforma. En 1861 comenzaron a discutirse nuevamente las reformas constitucionales, el tema del voto directo para la elección de todos los funcionarios públicos predominó, al exponerse que "Tiempo es ya de que los ciudadanos depositando sus votos en la mesa del sufragio designen a las personas que ejecuten su voluntad consignada en la ley fundamental que con tanto heroísmo han defendido y que tan sabiamente conservarán intacta o modificarán sus elegidos". ${ }^{43}$ También, llamaron la atención sobre la soberanía actual y la necesidad del sufragio universal:

[...]una soberanía ridícula, ejercida por un soberano a quien se declara estúpido o malvado[...] Si con tiempo no se otorgan al pueblo, este y otros principios, sacudirá algún día el oropel con que se ha hecho brillar a sus ojos sus derechos que nadie se los puede ya disputar[...]saldrá de su letargo y verá clara la luz de su justicia y emprenderá otra lucha mil veces más sangrienta que la pasada, para mejorar su condición material y positiva y para obtener no una sombra de libertad y democracia, sino la libertad y democracia misma[... $]^{44}$

Una vez más los municipios formaron parte de estos debates con sus observaciones al proyecto de reformas constitucionales -propuesto por el legislativo estatal- centrando su atención en las modificaciones y la elección directa de los cargos del Poder Judicial. La asamblea municipal de Sánchez Román rechazó todo tipo de cambios hasta que no se emprendiese la reforma general de la constitución por el Soberano Congreso del Estado, pues las "particulares además de ser imperfectas producen más daño que provecho, embrollando más de lo que está nuestra legislatura particular"; por tanto, solicitaron "se deje intacta hasta que esa propia soberana corporación tenga a bien poner remedio a todos los graves males que de ella se originan y especialmente el de expedir leyes no constitucionales sin las observaciones de los pueblos". ${ }^{45}$ El municipio de Villa de Cos consideró: "nada más justo, que seguir con igualdad los principios democráticos sujetando a elección popular el nombramiento del poder judicial". Mientras que el de Sain Alto precisó: "nada más conveniente y adecuado a estas instituciones en concepto de esta I. corporación, cuando se trata de elegir el poder judicial, es decir, de

\footnotetext{
${ }^{42}$ G. Huitrado, "Zacatecas", p. 47-58.

${ }^{43}$ AHEZ, Poder legislativo, Actas de sesiones, 21 de enero de 1861.

${ }^{44}$ AHEZ, Poder Legislativo, Actas del congreso, Manifiesto de conformidad por las reformas a los artículos 60, 61 y 62 de la constitución del Estado, 1862.

${ }^{45}$ AHEZ, Poder Legislativo, Comisión de Constitución, Manifiesto de conformidad por las reformas a los artículos 60, 61 y 62 de la Constitución del Estado, Sánchez Román.
} 
nombrar a aquellos C.C. que deben hacer la aplicación de estas mismas leyes, el pueblo los elija depositando su confianza por medio de sus electores". ${ }^{46}$

Estos cambios no pudieron concretarse en la práctica de manera inmediata, debido a la Guerra de Reforma y posteriormente a la Intervención Francesa en el país. No sería sino hasta 1869 que se retomarían las discusiones y se pondrían en práctica los preceptos constitucionales.

\section{3.- Del papel a la práctica: la aplicación y reforma de los preceptos constitucionales en un contexto de posguerra, 1869-1874}

Tras la restauración de la República en 1867, la reivindicación de la Constitución Federal de 1857 se convirtió en un elemento fundamental para una adecuada marcha administrativa y la obtención de los anhelados bienes establecidos por la constitución. Los editores del periódico La linterna mágica -publicado en la ciudad de Zacatecas y dirigido por Miguel Ruelas, Cayetano Arteaga, Eduardo G. Pankhurst, Ramón Guerra, Severo Cosío y Jesús Sánchez de Santa Anna- lo dejaron ver en una publicación de mayo de 1868 al señalar: "la constitución ha debido ser la única luz que nos guíe la obra laboriosa de la reorganización" pues sólo siguiendo "el amplio y despejado camino que marca ese código supremo será como hemos de llegar a la consecución completa de tan inapreciables bienes". Se mantuvo firmemente la idea de que "un minucioso apego por parte del gobierno a los preceptos de la constitución, y un respeto profundo a las garantías que aquélla asegura, a la vez que una saludable energía para reprimir los abusos que a su sombra se pretenden cometer, bastará para hacer regular y expedita la marcha de la constitución". ${ }^{47} \mathrm{El}$ puntual seguimiento a los mandatos constitucionales había representado, en el ideario liberal, una de las cuestiones básicas para alcanzar la libertad del individuo, base fundamental del liberalismo mexicano; sólo a través de una constitución escrita se podía poner límites a la autoridad del gobierno central $\mathrm{y}$, de esa forma, asegurar las garantías individuales. ${ }^{48}$ Una vez más, tras un escenario convulso se apostó por realizar reformas a la Constitución local de 1857.

La Comisión de Constitución formada por Acosta, Ferniza y Sánchez de Santa Anna, fue la encargada de realizar el proyecto para dichas modificaciones. Las discusiones se volcaron hacia dos temas centrales: la modificación del artículo 50 constitucional y las elecciones directas. Se redujo nuevamente el número de habitantes para formar un "ser político" y acceder a los ejidos; en esta ocasión se determinó que toda población ubicada en territorio particular con un mínimo de 500 habitantes podía crear una congregación, cuya dotación de ejidos sería expropiada e indemnizada al

\footnotetext{
${ }^{46}$ AHEZ, Poder Legislativo, Comisión de Constitución, Manifiesto de conformidad por las reformas a los artículos 60, 61

y 62 de la Constitución del Estado, 1862.

${ }^{47}$ HNDM, La linterna mágica, Zacatecas, sábado 16 de mayo de 1868, Tomo I, No. 3.

${ }^{48}$ Charles Hale, La transformación del Liberalismo en México a fines del siglo XIX, México, Vuelta, 1991.
} 
propietario. ${ }^{49}$ También, se modificaron el artículo 13 referente a la elección de diputados, el 35 relativo a la elección de gobernador y el 60 concerniente al nombramiento de los Ministros y Fiscales del Supremo Tribunal de Justicia, como se muestra en la tabla 3.

Tabla 3: Forma de elección de los tres poderes estatales en la legislación estatal

\section{Constitución Política del Estado Constitución Política del Estado Libre} Libre de Zacatecas, 1857 de Zacatecas, 1869

Art. 13 La elección de los diputados será indirecta en primer grado, en los términos que diga la Ley Orgánica Electoral.

Art. 35 La elección de Gobernador será indirecta en primer grado Art. $60 \mathrm{El}$ nombramiento de los Ministerios y Fiscal del Supremo Tribunal de Justicia, y el de los Jueces de Primera Instancia se hará por el gobierno a propuesta en terna del $\mathrm{H}$. Congreso. El nombramiento de interinos se hará por todo el tribunal si la falta no excede de seis meses, y si excede se hará en los términos que establece la primera parte de este artículo.

Fuente: G. Huitrado, “Zacatecas”, pp. 60-64. APLEZ, Actas de sesiones, Libro de actas del primer periodo de sesiones ordinarias 1868, 13 de abril de 1868 .

Los cambios tuvieron como objetivo ampliar la participación ciudadana, y de esta forma, poner en práctica una verdadera democracia. Mientras los artículos 35 y 60 no generaron discusión al interior del legislativo y fueron aprobados de inmediato por unanimidad, el art.13 sí propició algunos comentarios tras la posición del ejecutivo estatal a cargo de Severo Cosío, quien consideró al pueblo incapaz de ejercer este derecho. El diputado García Elías expuso cómo esta reforma era "una consecuencia lógica de los principios que profesamos"; por ese motivo, vio necesario "que a los colegios electorales se les quite ese poder arbitrario y aristocrático que ejercen", pues la experiencia electoral visibilizaba su superioridad respecto "al pueblo que los nombra y despreciando su sana y acertada inspiración, burlada la confianza que han depositado en ellos". Por su parte el diputado Acosta expresó la importancia de la elección directa, al tratarse de "la más conforme a nuestras instituciones", aunque en ésta "como en las demás innovaciones que pretendemos hacer hemos de tropezar con el «no es tiempo»". Los legisladores creyeron que se trataba de un adelanto en los derechos del pueblo y cuestionaron al gobernador preguntando: “¿cuándo sería capaz?”. La

${ }^{49}$ Archivo Histórico del Poder Legislativo de Zacatecas, (Zacatecas, México) (AHPLEZ), Actas de sesiones, Libro de actas del primer periodo de sesiones ordinarias 1868, 13 de abril de 1868. 
balanza se inclinó por la aprobación, pues una vez hechas las votaciones se obtuvo por unanimidad ${ }^{50}$.

Estas modificaciones fueron resultado de un largo proceso que buscó ampliar el número de ciudadanos y la participación de los pueblos en la elección de funcionarios. Desde 1850 se sugirió y llegó a plantearse en la legislatura la intervención de los ayuntamientos para la elección de los diferentes cargos políticos; la conquista de estos derechos se fue dando de manera paulatina, con la disminución de restricciones para poder ser considerado como ciudadano y la determinación de que el cargo de jefe político fuera a través de elección popular, ambas establecidas en la Constitución de 1857; y finalmente, en 1869 con el procedimiento de elección directa para los cargos públicos de los cuatro poderes. Tras estas reformas constitucionales, el estado se convirtió en un escenario de dos momentos históricos que marcaron el contexto político local: las solicitudes de los pueblos para erigirse en congregaciones y las primeras elecciones directas.

A partir de 1868 comenzaron a llegar una serie de demandas por parte de los pueblos, para el establecimiento de las congregaciones y la dotación de ejidos, creando un ambiente de disputa entre los legisladores, debido a los procesos de expropiación que implicó su creación. Se desencadenaron una serie de conflictos que derivaron en diferentes juicios de amparo promovidos por los propietarios, algunos de los cuales tenían cargos en el Congreso local, como fue el caso de Gabriel García Elías principal opositor del artículo 50. ${ }^{51}$ Este proceso en conjunto con las elecciones directas, fueron determinantes para la división política en el seno del grupo liberal zacatecano.

Las primeras votaciones estatales se llevaron a cabo en agosto de 1869, dejando ver las diferentes posturas al interior del legislativo estatal en torno a su funcionalidad. Se creó un escenario de disputa entre los grupos políticos que detentaron el poder en Zacatecas y reflejó las dificultades que produjo la introducción de esta innovación a la carta constitucional. Como bien sostiene Mariana Terán, los procesos electorales representaron un eficaz mecanismo para lograr la legitimación de los grupos políticos, mientras que las redes funcionaron como trampolín para la formación de círculos políticos que buscaron participar en el contexto electoral; fueron tales prácticas movilizadoras las que gestaron "una cultura electoral mexicana que ayudó a la construcción de la legitimidad de los distintos grupos en el poder"52.

Una vez concluidas las votaciones en el estado, aparecieron dos visiones completamente opuestas sobre el resultado del proceso: por una parte, el gobierno manejó un discurso público que expuso el triunfo democrático, por ser la primera vez "que nuestro Estado ofrece al mundo el grandioso

\footnotetext{
${ }^{50}$ AHPLEZ, Actas de sesiones, Diputación permanente 1868, 28 de diciembre de 1868.

${ }^{51}$ AHPLEZ, Actas de sesiones, Actas de sesiones del Congreso, 11 de enero de 1868

${ }^{52}$ Mariana Terán Fuentes, "Una planta exótica en la política zacatecana: las primeras elecciones directas en 1869”, en Fausta Gantús y Alicia Salmerón (coords.), Campañas, agitación y clubes electorales: organización y movilización del voto en el largo siglo XIX mexicano, México, Instituto Mora, INEHRM, 2019, pp. 269-313.
} 
espectáculo de las elecciones directas", pues sólo de esta forma "el único mandante soberano ofrece en toda su extensión y plenitud el uso de sus derechos escogiendo libremente a sus mandatarios". Se enalteció la incursión de Zacatecas a la democracia legítima, reconociendo a la legislatura sus prácticas verdaderamente liberales. Según las estadísticas del gobierno, 66 mil ciudadanos participaron presentando sus candidatos para Diputados, Magistrados y Jueces; esto correspondía a la sexta parte de la población del estado, incluidos niños, mujeres y todos aquellos que no tenían el derecho al voto. Así describieron el entusiasmo ciudadano durante el proceso:

[...]se ha despertado el patriotismo, se ha movido en algunos puntos hasta el entusiasmo y el interés de las localidades todas, ha tomado un incremento notable cuando se han visto llamadas para señalar ellas mismas directamente las personas que hayan de procurar su dicha y bienestar, en todas las escalas que por ahora ha podido comprender la convocatoria respectiva; es ya innecesaria la representación ajena para el ejercicio de funciones que pueden desempeñar los CC. por sí propios; la elección directa es una conquista hecha por nosotros $[\ldots]^{53}$

El informe señaló que los actos electorales ocurrieron sin contratiempos. Ni protestas ni quejas habían sido reportadas por las autoridades municipales; y aunque se reconocieron las prácticas y maniobras comunes para ganar las elecciones, exaltaron el disimulo y la prudencia de la población "sin tener la policía otro participio que el de evitar un rompimiento que pudiera alterar el orden público y proteger bajo su égida poderosa a los CC. encargados por la ley para recibir la votación, como también la libertad de los que sufragaban" 54 .

En el transcurso de las sesiones ordinarias del congreso estatal, se fue haciendo visible la otra versión sobre los comicios. Primero, el diputado Torres llamó la atención acerca del número de sufragios efectuados para las elecciones del Supremo Tribunal de Justicia. Éste no correspondía siquiera a la tercera parte del censo que daba el estado, "y como para declarar electo Magistrado a un ciudadano, se necesita que reúna, según la ley electoral, la mitad y uno más, de los votos para que deben emitir todos los ciudadanos aptos para votar". Por tales motivos, consideró la elección nula y puso en la misma situación al resto de los poderes estatales. Otros diputados como Acosta se manifestaron en contra de esta postura, desacreditaron sus observaciones "porque pretender negar que las personas que han obtenido treinta y cinco y cuarenta y ocho votos no tienen una mayoría absoluta, cuando ha habido un número de sesenta y seis mil votantes, es querer negar una verdad". También fundamentaron su posición argumentando que no se podían computar los votos no emitidos, ni obligar a votar a todos aquellos quienes no pudieran o quisieran ejercer ese derecho ${ }^{55}$.

\footnotetext{
${ }^{53}$ AHPLEZ, Libro de actas de las sesiones extraordinarias del H. Congreso, 1-15 de mayo 1869 y 16-30 de agosto 1869.

${ }^{54}$ AHPLEZ, Libro de actas de las sesiones extraordinarias del H. Congreso, 1-15 de mayo 1869 y 16-30 de agosto 1869.

${ }^{55}$ AHPLEZ, Libro de actas de las sesiones extraordinarias del H. Congreso, 1-15 de mayo 1869 y 16-30 de agosto 1869.
} 
No obstante, estas dos versiones, sí se presentaron disturbios durante las votaciones. Se habló de algunos excesos en la capital del estado, de la violación a la ley electoral y a los derechos de los ciudadanos a la hora de elegir a la persona de su preferencia. En algunas municipalidades del partido de la capital el número de votantes fue una "minoría insignificante de ciudadanos"; y en otras, se reportó la presencia y presión de las fuerzas armadas y autoridades locales. Por estas razones, el diputado García Elías se pronunció en contra del acta que verificaba los resultados del proceso:

[...] parece lógico que la elección del partido de la capital debe declararse nula, cualesquiera que sean los ciudadanos que hayan sido electos. No hallo esta cuestión de personas sino de principios. Si no declaramos de nulidad las citadas elecciones establecemos un mal precedente para lo futuro, pues se seguirán haciendo cosas semejante o peores[...] y de esta manera no nos consolidaremos jamás, siendo una burla nuestras leyes y nuestra libertad[...] mi opinión no será escuchada; la mayoría del congreso resolverá que se infrinja la ley, que el pueblo sea humillado; pero yo protesto contra tal procedimiento y declaro ante el pueblo que me nombró su representante, que nunca me haré cómplice del despotismo ${ }^{56}$.

La presencia de las fuerzas armadas generó diferentes interpretaciones por parte de los legisladores. Mientras Acosta habló de una computación de votos apegada a las leyes electorales y justificó la permanencia de la fuerza pública por las calles de la ciudad, "a consecuencia del plan adoptado por uno de los círculos políticos para apoderarse de las mesas a todo trance"; Román se mantuvo a favor de la exposición del diputado Elías, pues "el mismo gobierno empleó su influencia y las fuerzas de sus armas para que dicha elección recayera en los candidatos que más le conviniera" y como "es preciso que no haya coacción directa ni indirecta de ningún género según la ley respectiva[...] creo por todo esto que el acta fue nula y repito que protesto contra él". ${ }^{57}$ No obstante estas manifestaciones en contra, el acta de resultados electorales fue aprobada, pues únicamente Talancón, García Elías y Román votaron en contra. ${ }^{58}$

Tras esta primera experiencia de elecciones directas y demandas por la creación de congregaciones y dotación de ejidos, el escenario político local se modificó. En 1870 las peticiones se detuvieron y todos los procesos en curso fueron frenados. Trinidad García de la Cadena, dirigente del grupo liberal que se encontraba en el poder, se unió al Plan de San Luis, propiciando que el presidente Benito Juárez declarara a Zacatecas en estado de sitio y

\footnotetext{
${ }^{56}$ AHPLEZ, Libro de actas de las sesiones extraordinarias del H. Congreso, 1-15 de mayo 1869 y 16-30 de agosto 1869.

${ }^{57}$ AHPLEZ, Libro de actas de las sesiones extraordinarias del H. Congreso, 1-15 de mayo 1869 y 16-30 de agosto 1869. En las próximas elecciones la jefatura política de Jerez informó que de las 47 secciones electorales en que está dividido el municipio de Ciudad García, solamente en 11 se verificó la elección de jueces de paz y dos munícipes que debió tener lugar el último domingo de Abril. También llamó la atención la influencia de los propietarios de haciendas y ranchos en las decisiones de los pueblos. AHPLEZ, Actas, IV Legislatura, Libro de Actas del Congreso del Estado, marzo 1873-agosto 1874

${ }^{58}$ AHPLEZ, Actas, IV Legislatura, Libro de Actas del Congreso del Estado, marzo 1873-agosto 1874. La jefatura política de Jerez informó que de las 47 secciones electorales en que está dividido el municipio de Ciudad García, solamente en 11 se verificó la elección de jueces de paz y dos munícipes que debió tener lugar el último domingo de abril.
} 
nombrara como nuevo gobernador y comandante militar a Gabriel García Elías. ${ }^{59}$ El congreso se conformó por otros legisladores que frenaron las solicitudes de los pueblos y dejaron ver las inconformidades para mantener este tipo de procedimientos electorales; llegándose a proponer el regreso de las elecciones indirectas.

Para 1873 los diputados llamaron la atención sobre el número de ciudadanos votantes, principalmente en lo referente a las elecciones del poder judicial. El C. Márquez hizo referencia al reducido número de ciudadanos que ejercieron su derecho al voto en los comicios del juez de letras de Sombrerete, éstos no representaban la mayoría de los que tenían el derecho a votar en aquel partido; por esta causa solicitó la anulación de la elección, advirtiendo: "no es dudoso que de esta manera llegara alguna vez a darse el caso de que un número de votantes verdaderamente insignificante sea, el que haga una elección". Las debilidades del procedimiento de elección directa parecían tan evidentes que el diputado Sandoval llegó a proponer la reforma de la ley constitucional, para declarar el voto como una obligación y no un derecho ${ }^{60}$.

El 17 de enero de 1873 fue presentado un nuevo proyecto de reformas constitucionales elaborado por los diputados Manuel S. Caballero, Yáñez y Méndez, cuyo planteamiento principal consistió en implementar nuevamente el procedimiento de elección indirecta en primer grado. Sus ideas se fundamentaron en razones como la falta de conocimiento del pueblo para emitir su voto "a aquellas personas que más lo merezcan por su ilustración y saber"; y la facilidad con que se deja engañar por otras personas "que haciendo valer su posición social tiene interés particular en que la elección recaiga en determinado individuo". Durante los siguientes meses estuvo circulando entre las municipalidades para su aprobación. Las asambleas que se mantuvieron a favor de la propuesta por considerarla suficientemente fundamentada en la experiencia, fueron: Ciudad García, Escobedo, Tepetongo, San José, Calera y Chupaderos. Por su parte, Zacatecas, Concepción del Oro, Pánuco y Fresnillo estuvieron en contra.

La municipalidad de Zacatecas fue mucho más explícita a la hora de exponer sus razones. La elección directa era considerada por los munícipes como la más adecuada al espíritu de las instituciones democráticas, debido a la participación real que el pueblo tenía a la hora de nombrar a sus mandatarios; por ello, no estuvieron de acuerdo en derogarla a fin de evitar las dificultades que se habían presentado ante el progreso de las instituciones republicanas, por el contrario:

[...] lo natural, lo lógico, lo verdaderamente patriótico y digno de alabanza será perfeccionar el paso avanzando corrigiendo los defectos que se noten en las leyes reglamentarias, quizá inspiradas y ejecutadas

\footnotetext{
${ }^{59}$ Salvador Vidal, Continuación del bosquejo histórico de Zacatecas del Señor Elías Amador, Tomo Cuarto 1867-1910, 1959, p.39.

${ }^{60}$ AHPLEZ, Actas, IV Legislatura, Libro de Actas del Congreso del estado, marzo 1873-agosto 1874.
} 
bajo la impresión de pasiones políticas nacidas de las circunstancias. Por eso[...] $1^{\text {a }}$ no es de aceptar la reforma constitucional consultada al Congreso del Estado[...] 2 $2^{\mathrm{a}}$ la elección directa deberá reglamentarse en términos que, garantizando el respeto que se debe al voto del pueblo, devuelva a éste la confianza y con ella el interés que debe tener en la elección del personal de los poderes públicos ${ }^{61}$.

Por su parte, el municipio de Fresnillo resaltó cómo las poblaciones más alejadas tenían mayores dificultades para emitir su voto, porque no distinguían a las personas más capaces para desempeñar los cargos y no comprendían la importancia de los puestos púbicos. Especificaron las desventajas tanto de la elección indirecta como de la directa, la primera por proceder de un colegio electoral, nombrado por elección directa y formado por personas residentes en las haciendas o rancherías de los municipios y muy pocas de los poblados, "así que aunque los electores sepan leer y escribir no se puede decir por esto, que tengan el necesario conocimiento de los individuos, que por su capacidad, patriotismo y virtudes cívicas sean dignos de ocupar el puesto que se les va a confiar", propiciando también "que lejos de corresponder debidamente a la confianza que en ellos se depositó, procurando nombrar un ciudadano digno y capaz, a la vez nombran a otro que no lo sea, o aquél que un interesado les señale". Por estas razones la elección directa les pareció más adecuada, pues si optaban por la indirecta "nunca veremos que el pueblo se instruya, ni se crea siquiera obligado a conocer a las personas que puedan llegar a ser quizá los depositarios de su porvenir", mientras que con la directa "tropezando con los mismos errores, ganamos cuando menos avanzar en el terreno de la civilización"62.

La asamblea municipal de Pánuco se mantuvo en una posición media, después de un minucioso examen de las reformas se inclinó porque el nombramiento de los funcionarios públicos se hiciera por elección directa y popular, a excepción de los Magistrados del Supremo Tribunal de Justicia, quienes debían ser nombrados por las asambleas municipales del partido correspondiente. Reconocieron los obstáculos de la "ignorancia generalizada en el pueblo" que sólo se logaría disipar a través de leyes sabias y fondos suficientes, allanando el terreno "para la marcha regular y progresiva al perfeccionamiento de nuestras instituciones republicanas". ${ }^{63}$ Finalmente señalaron:

[...]con la constante práctica, el pueblo comprenderá más su soberanía que le indica la ley relativa y que le ofuscaría su derogación; para robustecer nuestra opinión expondremos que antes de la promulgación de las leyes de reforma, el pueblo casi en general sólo conocía obligaciones religiosas y no las que lo ligan con el Estado; y con la permanencia en vigor de estas leyes, se ha ilustrado de tal manera que

\footnotetext{
${ }^{61}$ AHPLEZ, Actas, IV Legislatura, Libro de Actas del Congreso del estado, marzo 1873- agosto 1874

62 AHPLEZ, Actas, IV Legislatura, Libro de Actas del Congreso del estado, marzo 1873- agosto 1874

${ }^{63}$ AHPLEZ, Actas, IV Legislatura, Libro de Actas del Congreso del Estado, marzo 1873-agosto 1874.
} 
notablemente se ve que hoy comprende sus deberes sociales y religiosos ${ }^{64}$.

Gracias a las resistencias las reformas no procedieron y la Constitución de 1869 se mantuvo vigente tal cual. El estudio reciente sobre el primer proceso electoral en el estado, realizado por Mariana Terán, permite visualizar mejor los alcances que tuvieron las elecciones directas. La autora plantea cómo la violencia que las caracterizó representa "una fórmula consensada por los grupos políticos para lograr legitimidad ante la sociedad", a través del conocimiento de la ley electoral y la planeación de estrategias. Inserta el caso zacatecano en un contexto nacional, advirtiendo que estados como Aguascalientes, Guanajuato, Michoacán, Oaxaca, Puebla, Sonora, Campeche, Coahuila, Chihuahua, Durango, Guerrero, Nuevo León, Sinaloa, Tamaulipas, Veracruz y Yucatán ya habían puesto en marcha este tipo de elecciones para algunos cargos; sin embargo, en ninguno se estableció de manera generalizada como sucedió en Zacatecas ${ }^{65}$.

\section{Reflexiones finales}

Sin duda, las condiciones bajo las cuales se fue definiendo el pacto federal a lo largo del siglo XIX, determinaron en buena medida las configuraciones del constitucionalismo durante el periodo de estudio. La soberanía de los estados permitió que cada entidad estatal creara su propio marco constitucional, en el que los municipios y sus ayuntamientos adquirieran una posición diferente respecto a la reformulación de su contenido, dando paso a la creación de un constitucionalismo plural que se definió por los procesos históricos locales. El caso de Zacatecas ilustra cómo las modificaciones importantes fueron producto de discusiones que llevaron periodos prolongados, para ser plasmadas en la constitución y posteriormente ponerse en marcha. Este proceso de planteamiento, deliberación y aplicación no fue para nada sencillo; por el contrario, tanto el escenario estatal como el nacional marcaron una directriz a partir de la circulación de ideas y de los continuos conflictos nacionales que en determinadas ocasiones llegó a frenarlo.

La importancia que mantuvieron las organizaciones municipales debido a su constante participación en los debates, fue determinante para los cambios que se vieron reflejados en las reformas constitucionales, pero también, en su aplicación posterior. Este análisis ha permitido mostrar la importancia de los procesos locales, pues, aunque se pueden apreciar similitudes en el contenido jurídico y fillosófico, lo cierto es que la política interna adquirió un peso crucial. El seguimiento a la implementación de las elecciones directas es un ejemplo; ya que a nivel nacional se venían dando las condiciones para poner en marcha esta clase de procedimientos electorales, siendo los estados los pioneros gracias a sus competencias administrativas.

${ }^{64}$ AHPLEZ, Actas, IV Legislatura, Libro de Actas del Congreso del Estado, marzo 1873-agosto 1874.

${ }^{65}$ M. Terán, "Una planta exótica", pp. 30-32. 
Si bien, la historia constitucional decimonónica es vista como el estudio de las leyes reguladoras de la organización política de un Estado, en conjunto con el pensamiento jurídico, político y filosófico, cuyas Constituciones son portadoras de la organización de los poderes públicos y el establecimiento de un sistema de competencias formales; también es cierto que las transformaciones experimentadas por la trayectoria de esta historia constitucional, se debieron a una interacción entre leyes, instituciones, actores y coyunturas políticas.

\section{Bibliografía:}

\section{Fuentes primarias}

Archivo Histórico del Estado de Zacatecas (AHEZ), Jefatura Política, Gobierno del estado, 1850.

AHEZ, Poder legislativo, Actas de Sesiones, 21 de Enero de 1861.

AHEZ, Poder legislativo, Actas de Sesiones del Congreso, 1850.

AHEZ, Poder Legislativo, Actas del Congreso, Manifiesto de conformidad por las reformas a los artículos 60, 61 y 62 de la constitución del Estado, 1862.

AHEZ, Poder Legislativo, Comisión de Constitución, Observaciones al proyecto de reformas a la Constitución por los partidos del estado, 2 de marzo de 1850.

AHEZ, Poder Legislativo, Comisión de Puntos Constitucionales, Acta de reformas a la constitución del Estado presentados por los diputados Sandoval, Cenoz y Ulloa, Junio-Julio, 1850.

AHEZ, Poder Legislativo, Comisión de Puntos Constitucionales Proyecto del acta de reformas presentada por el diputado Aranda, Julio de 1850.

AHEZ, Poder Legislativo, Leyes, Decretos y Reglamentos, 1849.

AHEZ, Poder Legislativo, Leyes, Decretos y Reglamentos, Proyecto de reglamento económico político y de policía para los partidos del estado y algunas observaciones, 1851.

AHMZ, Colecciones, Donación del Dr. José Enciso Contreras, Periódico, El Pobre Diablo.

AHPLEZ, Actas, Actas de sesiones del Congreso, 11 de enero de 1868.

AHPLEZ, Actas, Diputación permanente, 28 de diciembre de 1868.

AHPLEZ, Actas, Libro de actas de las sesiones extraordinarias del H. Congreso, 115 de mayo 1869 y 16-30 de agosto 1869. 
AHPLEZ, Actas, Libro de actas del primer periodo de sesiones ordinarias, 13 de abril de 1868 .

AHPLEZ, Actas, Libro de Actas del Congreso del Estado, marzo 1873-agosto 1874.

BPEA, Constitución Política del Estado Libre y Federado de Zacatecas, 1825.

HNDM, La linterna mágica, Zacatecas, sábado 16 de mayo de 1868, Tomo I, No. 3.

HNDM, El Pobre Diablo, Tlaltenango, Sábado 9 de mayo de 1856, Tom0o I, Núm. 23.

Unidad General de Asuntos Jurídicos, Acta Constitutiva de la Federación Mexicana, http://www.ordenjuridico.gob.mx/Constitucion/antecedentes.php

Unidad General de Asuntos Jurídicos, Acta Constitutiva y de Reformas, 18 de mayo de 1847, http://www.ordenjuridico.gob.mx/Constitucion/1843.pdf

Unidad General de Asuntos Jurídicos, Bases de la organización política de la República Mexicana 1843, http://www.ordenjuridico.gob.mx/Constitucion/antecedentes.php

Unidad General de Asuntos Jurídicos, Constitución Federal de los Estados Unidos Mexicanos 1824 , http://www.ordenjuridico.gob.mx/Constitucion/antecedentes.php

Unidad General de Asuntos Jurídicos, Constitución Federal de los Estados Unidos Mexicanos 1857, http://www.ordenjuridico.gob.mx/Constitucion/1857.pdf

Unidad General de Asuntos Jurídicos, Leyes Constitucionales 1836, http://www.ordenjuridico.gob.mx/Constitucion/antecedentes.php

Reglamento para el gobierno interior de los Partidos del Estado Libre de Zacatecas, 1825.

\section{Fuentes secundarias}

Andrews, Catherine, De Cádiz a Querétaro, historiografía y bibliografía del constitucionalismo mexicano, México, Fondo de Cultura Económica, Centro de Investigación y Docencia Económicas, 2017.

Arroyo, Israel, La arquitectura del estado mexicano: formas de gobierno, representación política y ciudadanía, 1821-1857, México, Instituto de Investigaciones Dr. José María Luis Mora, BUAP, 2011.

Bobbio, Norberto, Pensar la Democracia, México, Universidad Autónoma de México, 2007.

Carmagnani, Marcello, "El federalismo liberal mexicano", en Marcello Carmagnani (Coord.), Federalismos Latinoamericanos: México/Brasil/Argentina, México, El Colegio de México, Fideicomiso Historia de las Américas, FCE, pp. 135-179. 
Hale, Charles, La transformación del Liberalismo en México a fines del siglo XIX, México, Vuelta, 1991.

Huitrado Trejo, Guillermo (Coord.), Zacatecas y sus constituciones, Zacatecas, Gobierno del Estado, UAZ, 1996.

Ortega García, Ramón, "El derecho mexicano entre legalismo y constitucionalismo (anotaciones de historia constitucional)", en Estudios de Historia Moderna y Contemporánea de México, No. 50, 2017, pp. 5-25.

Pani, Erika, Una serie de admirables acontecimientos, 1848-1867, México, Educación y Cultura, Benemérita Universidad Autónoma de Puebla, 2013, pp.199.

Salinas Sandoval, María del Carmen, Política y sociedad en los municipios del estado de México (1825-1880), México, El Colegio Mexiquense, 1996.

Sordo Cedeño, Reynaldo, El congreso de la primera república centralista, México, El Colegio de México, Instituto Tecnológico Autónomo de México, 1993.

Terán Fuentes, Mariana, Bosquejo de un inmenso cuadro, liberalismo constitucional y formas de gobierno en Zacatecas, 1823-1845, México, UAZ, 2015.

Terán Fuentes, Mariana, "Una planta exótica en la política zacatecana: las primeras elecciones directas en 1869", en Fausta Gantús y Alicia Salmerón (coords.), Campañas, agitación y clubes electorales: organización y movilización del voto en el largo siglo XIX mexicano, México, Instituto Mora, INEHRM, 2019, pp. 269313.

Vazquez, Josefina Zoraida, "El federalismo mexicano, 1823-1847", en Marcello Carmagnani (Coord.), Federalismo Latinoamericanos: México/Brasil/Argentina, México, El Colegio de México, Fideicomiso Historia de las Américas, FCE, 1996, pp. $15-50$.

Vidal, Salvador, Continuación del bosquejo histórico de Zacatecas del Señor Elías Amador, Tomo Cuarto 1867-1910, 1959. 